\title{
Performance of Laboratory Critical Value on Clinical Laboratory Services in Supporting Patient Safety
}

Rosita, $\mathrm{L}^{1, *}$ Edy. $\mathrm{P}^{2}$

\author{
${ }^{1}$ Clinical Pathology Departement, Faculty of Medicine, Univesitas Islam Indonesia, Yogyakarta, Indonesia \\ ${ }^{2}$ Clinical Laboratory, Sragen Hospital, Sragen, Indonesia \\ *Corresponding author. Email: linda.rosita@uii.ac.id
}

\begin{abstract}
Background. Patient safety is a cornerstone of healthcare quality, including clinical laboratory services. Management of patients related to the patient safety includes all aspect of services, which covers the process of diagnosing, giving therapy, and predicting the prognosis. An important form of clinical laboratory service concerned about patient safety is a result of critical values. The aim of this study is to analyze the critical values of the patients which are expected to influence the patient safety. Materials and Methods. This study is an observational study with cross-sectional design. The research method used in this study is an analytic observation by pulling data from the laboratory information system and then processed using univariate anivariate analysis. Results. This research acquired 1000 critical value data, and 768 of them that fulfilled the requirements are analyzed. The percentage of critical value reported is $100 \%$. The categories of examination results consist of hematology, clinical chemistry, blood gas analysis, and electrolytes. The highest frequencies of critical values parameters are platelet count, sodium level, $\mathrm{pH}$ of blood and total bilirubin level. Turn-around times of 4 categories consecutively are blood gas analysis ( 1 minute 21 seconds), clinical chemistry ( 1 minute 23 seconds), electrolytes ( 1 minute 12 seconds), and hematology ( 1 minute 20 seconds). After that, this study performed ANOVA test resulted in $p>0.05$ which means that the four categories are not significantly different. Conclusions. Critical value reporting has been done well, but has not shown a difference between pediatric and adult patients. This result supports the patient safety program. It needs regular monitoring and evaluation (monev) on the management of laboratory critical values to impove patient safety.
\end{abstract}

Keywords: laboratory clinical value, patient safety, turn-around time

\section{INTRODUCTION}

Evaluating critical values reporting is an important way to improve the quality of laboratory services. Based on the Regulation of the Minister of Health of the Republic of Indonesia No. 1691 / Menkes / Per / VIII 2011 concerning hospital patient safety, the critical values must be reported immediately because they are related to patient safety at the hospital [1].

The critical value of a laboratory examination is a laboratory examination result that is very abnormal and can reflect a life-threatening situation, hence it needs to be reported immediately to the doctor who treats the patient for an immediate treatment [2]. The purpose of reporting the critical value of laboratory examinations is to warn medical personnel who treat patients, especially doctors, who are then expected to be able to act after receiving the report [3]. Therefore, it is necessary to develop a laboratory management system so that the reporting of this critical value can reduce the mortality rate.
This study examined and evaluated the reporting of critical laboratory values to the treating doctors based on the existing Standard Operating Procedures (SOPs), which must be done within 10 minutes after the laboratory results are released. Critical results of laboratory examinations are conveyed via telephone or message, from the laboratory staff to the doctor/nurse on duty for outpatients or to the doctor on duty/room nurse for inpatients. The critical results of laboratory examinations are then documented in medical records of the patients. The staff who reports the critical value results must record the reporting in a piece of a form. Evaluation of clinical indicators of Laboratory Critical Value must be carried out every 6 months. There are some obstacles considering that the reporting is still conducted manually, cauing a delay in the reportingand the undone documentation. Hence, an alarm system for reporting critical values of the laboratory was developed. 


\section{MATERIAL AND METHOD}

This data was obtained from the laboratory of Sragen Hospital in 2019. The data was evaluated retrospectively. From 1000 laboratory results which are released and have critical value, 768 of them can be analyzed.

\section{RESULTS}

Figure 1 presents data from 14 parameters with the frequency of critical values listed for each parameter. The three parameters with the highest frequency were creatinine, urea and glucose. The data was then classified into hematology and blood chemistry laboratory results, respectively in Figure 2 and Figure 3. The highest critical value of blood chemistry examination was creatinine, while for the hematological examination was hemoglobin.

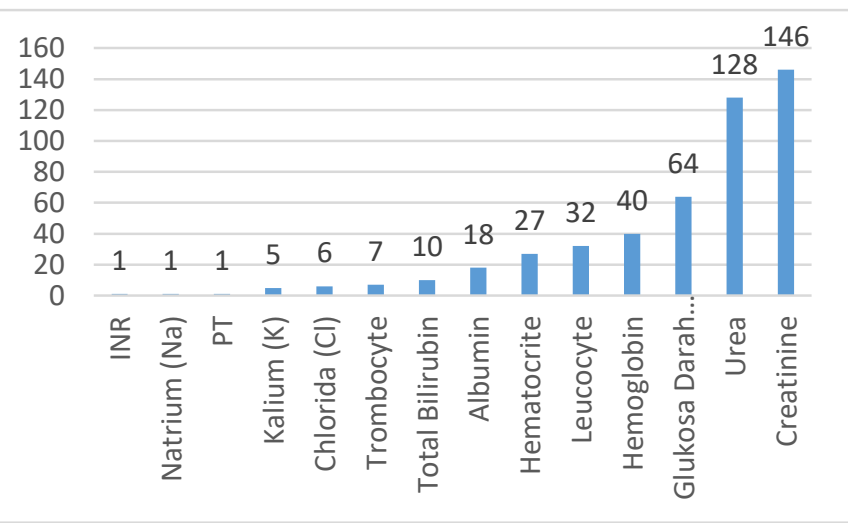

Figure 1. Parameters that often appear as Critical Values

The following figures shows the results of the critical value evaluation on a blood chemistry and hematology examination, respectively.

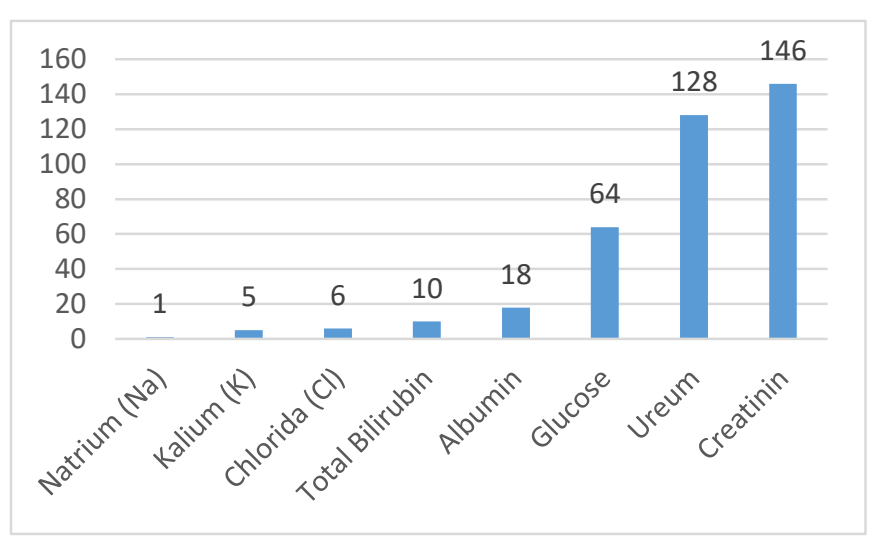

Figure 2. Critical Value of Blood Chemistry Results

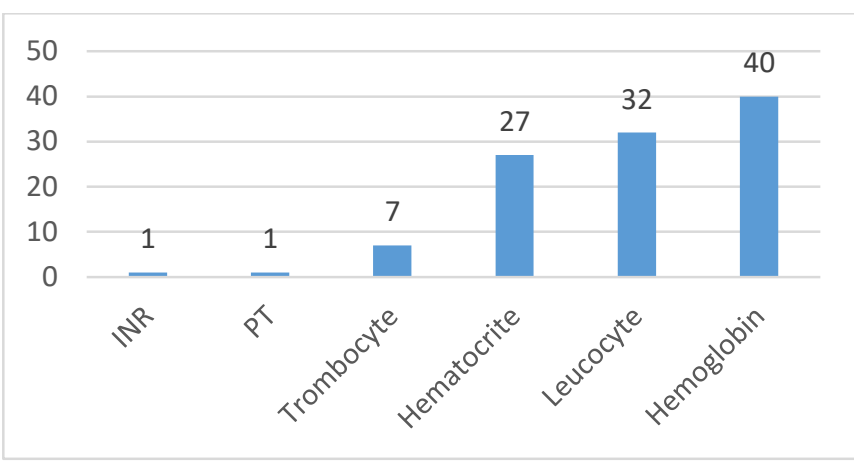

Figure 3. Critical Value of Hematology Results

The following table describes the critical value limits for various examinations at Sragen Hospital, both in adult and pediatric patients.

Table 1. Limits of Critical Value on Various Examinations for Adulit Patients at Sragen Hospital

\begin{tabular}{|l|l|l|l|l|}
\hline Adult Patients & $\begin{array}{c}\text { Lower } \\
\text { limit }\end{array}$ & $\begin{array}{c}\text { Upper } \\
\text { limit }\end{array}$ & $\begin{array}{c}\text { Frequency of } \\
\text { critical values }\end{array}$ & $\begin{array}{c}\text { Percen- } \\
\text { tage }\end{array}$ \\
\hline Hemoglobin & 5 & 20 & 40 & 8.62 \\
\hline Leukosit & 2 & 30 & 28 & 6.03 \\
\hline Hematokrit & 15 & 60 & 27 & 5.82 \\
\hline Trombosit & 20 & 800 & 7 & 1.51 \\
\hline Total bilirubin & - & 12 & 3 & 0.65 \\
\hline Albumin & 2 & 999 & 17 & 3.66 \\
\hline Natrium $(\mathrm{Na})$ & 120 & 160 & 1 & 0.22 \\
\hline Kalium $(\mathrm{K})$ & 2.5 & 7 & 5 & 1.08 \\
\hline Chlorida $(\mathrm{Cl})$ & 80 & 115 & 6 & 1.29 \\
\hline Glucose & 40 & 400 & 62 & 13.36 \\
\hline Ureum & - & 100 & 125 & 26.94 \\
\hline Creatinin & - & 4 & 143 & 30.82 \\
\hline
\end{tabular}

The results of laboratory examinations in children can be seen in the following table, which contains the profile as well as theupper and lower limits of critical values in clinical chemistry examinations.

Table 2. Limits of Critical Value on Various Examinations for Pediatric Patients at Sragen Hospital

\begin{tabular}{|l|l|l|l|l|}
\hline $\begin{array}{c}\text { Pediatric } \\
\text { Patients }\end{array}$ & $\begin{array}{l}\text { Lower } \\
\text { limits }\end{array}$ & $\begin{array}{l}\text { Upper } \\
\text { limits }\end{array}$ & $\begin{array}{c}\text { Frequency } \\
\text { of Critical } \\
\text { Values }\end{array}$ & Percentage \\
\hline Leucocyte & 2 & 30 & 4 & 18.18 \\
\hline PT & - & 20 & 1 & 4.55 \\
\hline INR & - & 4 & 1 & 4.55 \\
\hline Glucose & 40 & 400 & 2 & 9.09 \\
\hline Creatinin & - & 4 & 3 & 13.64 \\
\hline Ureum & - & 100 & 3 & 13.64 \\
\hline Albumin & 2 & 999 & 1 & 4.55 \\
\hline $\begin{array}{l}\text { Total } \\
\text { bilirubin }\end{array}$ & - & 12 & 7 & 31.82 \\
\hline
\end{tabular}


Table 1 and Table 2 show the lower and upper limits for critical values, the number of critical values, and the percentage of critical scores for adult and pediatric patients. Creatinine (30.82\%) was the highest percentage of all adult critical scores, whereas total bilirubin $(31.82 \%)$ was the highest of all pediatric critical scores.

Table 3. Target of Time of Critical Value Reporting at Sragen Hospital

\begin{tabular}{|l|l|l|}
\hline $\begin{array}{l}\text { Time } \\
\text { of reporting }\end{array}$ & Frequency & Target $\mathbf{( 1 0 0 \% )}$ \\
\hline Less than 7 minutes & 482 & 99.18 \\
\hline More than 7 minutes & 1 & 0.21 \\
\hline Not reported & 3 & 0.62 \\
\hline
\end{tabular}

Table 3 presents that among the 486 critical scores, the number of reports carried out in 7 minutes was 482 $(99.18 \%)$, more than 7 minutes was $1(0.21 \%)$, and the remaining 3 results $(0.62 \%)$ were not reported at all.

\section{DISCUSSIONS}

Laboratory results classified as critical value in laboratory services at Sragen Hospital were analyzed and presented in several forms. Critical value reporting can be defined as the time needed for laboratory staff to validate and report to the attending doctor who treats the patients. Each month the reporting time is evaluated based on the results of the division between the numerator and denominator. The numerator is the number of patients with reported critical value results, while the denominator is the total number of patients with critical value results. The target is $100 \%$.

Turn-around time (TAT) for laboratory critical values is set within 10 minutes after laboratory results are validated and reported to the treating doctor. The alarm system is implemented, the results of the critical values are conveyed via telephone or massage from the laboratory staff to the sending doctor/nurse on duty for outpatients or to the doctor on duty/ nurse for inpatients. The staff who reports the results of the critical value result fills the reporting form. Each morning the report forms are collected by the laboratory coordinator, so that it becomes discussion material for the hospital management morning report with other units. Evaluation of laboratory critical value is carried out every 6 months and is set as part of the laboratory's Key Performance Indicator (KPI). The target of critical value results reported is $100 \%$, meaning that all critical values must be reported in less than 10 minutes.

Table 3 shows that critical values reported in 2017 had not yet reached the target of $100 \%$. It was very fatal for the patient safety since the critical values could be lifethreatening so that the lives could not be saved. The reasons for critical values not reported were because the reported critical values were not recorded in a reporting form. In addition to that, there was a lack of understanding in SOPs of reporting critical values which had to be reported immediately in less than 10 minutes.

Most laboratory test results which are used in the process of diagnosing and giving therapy do not require immediate actions, but after some time the results change and lead to a serious condition of the patient. The term critical value was first defined by George D. Lundberg in 1972 as the result of laboratory tests that showed abnormal pathophysiological conditions that threaten the patient's life, so it is necessary to immediately inform the doctor who treats the patient so that an action could be taken [4].

Based on the problems presented, laboratory management proposes some suggestions: (1) re-educate laboratory staff regarding the urgency of critical values reporting and how to deliver them and write the report forms, (2) there needs to be a meeting to present critical value reports' condition every month in laboratory units and provide feedback to officers who have not been consistent in reporting critical values within a predetermined time of less than 10 minutes, and (3) design an alarm system that will assist officers when there are critical values automatically using LIS (Laboratory Information System).

In reporting the critical value, the first step taken is to recognize the critical value done by laboratory staff. Then, it is necessary to write clearly whether the results have been repeated or not repeated. Furthermore, the critical value is reported to the doctor who is responsible for taking care of the patient by telephone or other media [5].

In reporting the critical values for inpatients, the laboratory staff will make a phone call to the ward where the patient is treated and then report the values to the nurse. The nurse who receives the report will write the critical values and read it back to the laboratory staff. After that, the nurse reports to the doctor-in-charge of the patient who will also read it back to the nurse. The reporting process is complete and the nurse records the reporting time into the medical record [3].

When the alarm system is implemented, the center computers from the laboratory will provide a warning (reminder) in the form of sounds continuously, until the laboratory staff reports to the treating doctor or officers in the ward and records the hours, minutes and seconds when a phone call is done. Reporting laboratory critical values has been widely accepted as a factor affecting patient safety. Therefore, the reporting of critical values is one of the things that is assessed in the laboratory accreditation process [6].

This study consisted of 486 samples which were analyzed for 1 month at Sragen Hospital, Central Java, Indonesia. As per the literature, studies from other laboratories having a sample of 5,105,336 by Dighe et al., 54,878 were carried out by Sarita et al., 183,056 by Bhutani et al., and 5,723 by Abriol-Roca et al. In our study, the frequency of critical values varied from $0.22 \%$ for sodium to $30.82 \%$ for creatinine in adult patients. Meanwhile, in 
pediatric patients, the frequency varied from $4.55 \%$ for PT, INR, and albumin to $31.82 \%$ for total bilirubin. Overall without any classifications, creatinine, urea, and glucose are the three parameters that have the highest frequency [7-10].

In a previous study reported by Sarita et al, the parameter with the highest frequency was total bilirubin, followed by glucose and indirect bilirubin. The high proportion of total and indirect bilirubin was caused by the presence of PICU and NICU in the hospital. Meanwhile, Sragen Regional Hospital only has a PICU and a NICU, but each only has 2 beds, for a total of 4 beds. Among pediatric patients, total bilirubin may indeed has the highest frequency, but from the perspective of all patients, this study shows creatinine, urea, and glucose as the highest. [7].

Dighe et al. reported that potassium had the highest frequency, followed by Pro-Thrombin Time (PTT) and platelet count. These findings may be associated with the risk of hemolysis at the time of sampling in pediatric patients. In our study, there were no results for potassium. This research needs to have a longer duration to get more data regarding potassium [8].

Report from another study by Abriol-Roca et al. had a slightly different result. Oxygen partial pressure had the highest frequency, followed by potassium and platelet count. This result was almost the same as the result reported by Dighe et al. The cause of the partial pressure of oxygen had a high proportion because the highest percentage of critical values was found for inpatients in the ICU, including blood gas analysis. Whereas at the Sragen Regional Hospital, blood gas analysis was not part of the parameters analyzed in the study [10].

The percentage of critical value reported within 7 minutes in this study was $99.18 \%$. This was because the system is built prety well. Hence, it is important to prioritize critical values to immediately be notified to the doctor or other officer in charge.

Some considerations need to be made because not all critical values might be life-threatening in some cases. It must be identified to have efficient communication in reporting critical values, such as high troponin in postoperative patients and high creatinine yields for patients on routine hemodialysis. Both do not require urgent communication between the laboratory and the doctor. Changes in laboratory results on a parameter that are fast and unexpected should also be added to the protocol because they can signal a deterioration in conditions that could harm the patient [7].

Sragen Hospital uses the same upper and lower limits for adult and pediatric patients, whereas in previous studies by Bhutani and Bhutani, it has different upper and lower limit for identifying critical values. Even the lower and upper limits for glucose in newborns and children are different, and so are the glucose limits in adults. However, in studies by Sarita et al., Dighe et al., And Abriol-Roca et al, they did not differentiate the limits [7-10].

A study by Don-Wauchope et al. explained that in pediatric patients, there is a different list of critical values.
For example, low and high glucose for newborns less than 3 days old is different from those for newborns older than 3 days. The lists of different critical values for potassium vary for neonates and children, so do the lists of critical values for bilirubin, free T4, calcium, and ammonia. The critical value of bilirubin is based on Canadian Pediatric Society (CPS) guidelines on neonatal hyperbilirubinemia. There should be further considerations because pediatric patients are not miniature of adult patients, so for research in Sragen Hospital, the list of critical values must be adjusted because it will improve the quality of patient management. In other studies, the upper and lower limits also vary. In general, the limits should be adjusted based on the hospital setting and the age of patients [11].

\section{CONCLUSION}

In this study, adult patients' creatinine was the highest critical value which is followed by urea. Whereas in children, total bilirubin was the parameter with the highest frequency which is followed by leukocytes. Timely reporting, an age-adjusted list of critical values, consideration of some cases that do not need to be reported, are important in terms of patient safety.

Thus, the different frequency and reporting of critical values was caused by differences in conditions at the hospital. This study requires further analysis to find high frequency parameters to investigate whether they have the same underlying cause in order to provide more effective intervention. It is also important to establish a list of critical values that were consulted by a doctor and set limits based on the age. Some considerations are required for some unnecessary reportings. All of these steps can help modify patient management so that they will be of benefit in the long term.

This study did not examine further the direct clinical outcomes on patient safety. It is limited to interviews with doctors who treat patients regarding the application of critical value reporting.

The achievement of critical values improves after the alarm system is implemented. The critical value alarm system is useful for increasing a fast and accurate reporting and also able to reduce mortality, as an effort to improve patient safety. The alarm system in Sragen Hospital can be used as a best practice for other laboratories to implement.

Sragen Hospital has an effective time to report critical values, but does not yet have a list of critical values that are adjusted for adult and children patients. Further research is needed to find a common ground of the same parameters for a better intervention.

\section{CONFLICT OF INTEREST}

The authors declare that they have no conflict of interest.

\section{ETHICAL APPROVAL}

All procedures performed in this study involving human 
participants were in accordance with the ethical standards of the institutional and/or national research committee as well as the 1964 Helsinki declaration and its later amendments or comparable ethical standards.

\section{REFERENCES}

[1] Regulation of the Minister of Health of the Republic of Indonesia No. 1691 / Menkes / Per / VIII 2011. 2011.

[2] Murari M. Reporting critical laboratory values in hematology. Indian Journal of Hematology and Blood Transfusion. 2008;24(2):81-2. http://doi.org/10.1007/s12288-008-0026-7

[3] Parl FF, O'Leary MF, Kaiser AB, Paulett JM, Statnikova K, Shultz EK. Implementation of a closed-loop reporting system for critical values and clinical communication in compliance with goals of the joint commission. Clinical Chemistry Journal. 2010;56(3):417-23.

[4] Emancipator K. Critical Values: ASCP Pratice Parameter. American Journal of Clinical Pathology. 1997;369(1):168999. http://doi.org/10.1093/ajcp/108.3.247

[5] Rocha BCB, Alves JAR, Pinto FPD, Mendes ME, Sumita NM. The critical value concept in clinical laboratory. The Journal Brasileiro de Patologia e Medicina Laboratorial. 2016;52(1):17-20. http://doi.org/ 10.5935/16762444.20160008
[6] Rensburg MA, Nutt L, Zemlin AE, Erasmus RT. An audit on the reporting of critical results in a tertiary institute. Annals of Clinical Biochemistry. 2009;46(2):162-4. http://doi.org/ 10.1258/acb.2008.008182

[7] Sarita JM, Tailor PB. Analysis of Laboratory Critical value Reporting Pattern at clinical biochemistry laboratory of Tertiary health care Center. International Journal of Biomedica and Advance Research. 2015;6:617-22.

[8] Dighe AS, Rao A, Coakley AB, Lewandrowski KB. Analysis of laboratory critical value reporting at a large academic medical center. American Journal of Clinical Pathology. 2006;125(5):758-64. http://doi.org/10.1309/R53X-VC2U-5CH6-TNG8

[9] Bhutani N, Bhutani N. A Study of Analysis of Critical Values at Emergency Biochemistry Laboratory in a Tertiary Care Hospital in India. Journal of Evolution of Medical and Dental Sciences. 2020;9(12):957-60. http://doi.org/10.14260/jemds/2020/206

[10] Abriol-Roca A, Corral-Comesana S, Cano-Corres R, CastroCastro MJ, Dastis-Arias M, Dot-Bach D. Analysis of laboratory critical values at a referral Spanish tertiary university hospital. Biochemical Medicine. 2018;28(3):1-9. http://doi.org/10.11613/BM.2019.010704

[11] Don-Wauchope AC, Wang L, Grey V. Pediatric critical values: Laboratory-pediatrician discourse. Clinical Biochemistry. 2009;42(16-17):1658-61. http://dx.doi.org/10.1016/j.clinbiochem.2009.06.029 